\title{
Maximum Power Point Tracking Technique Based on Particle Swarm Optimization Method Applied to a Single-Phase Grid-Tied Photovoltaic System
}

\author{
F. M. Oliveira, S. A. O. Silva, F. R. Durand and L. P. Sampaio \\ Federal Technological University of Paraná - UTFPR-CP \\ Department of Electrical Engineering \\ Av. Alberto Carazzai, 1640, CEP-86300-000 Cornélio Procópio-PR (Brazil) \\ Phone: +55 (43) 3520-4000, Fax: +55 (43) 3520-4010 \\ E-mails: fernandomarcos.eng@hotmail.com, augus@utfpr.edu.br, fabio.durand@utfpr.edu.br, sampaio@utfpr.edu.br
}

\begin{abstract}
This paper deals with a study of a maximum power point tracking (MPPT) technique based on the Particle Swarm Optimization (PSO) method, which is applied to a single-phase grid-tied photovoltaic system. Since photovoltaic panels have nonlinear voltage-current characteristic curves, when they are submitted to partial shading conditions, it is possible appear distinct local and global maximum power points. On the other hand, most traditional MPPT methods are not able to find the maximum global point for extraction the maximum power provided by the PV array. Therefore, in order to overcome this problem, MPPT-PSO based method is used for obtaining the maximum global point, maximizing the power extraction in the photovoltaic arrangements. Numerical simulations are presented to demonstrate the effectiveness of the proposed MPPT technique, when it is compared with the well-known Perturb and Observe (P\&O) MPPT technique.
\end{abstract}

\section{Key words}

Particle swarm optimization method, Perturb and observe MPPT technique, PV array, Grid-tied PV system.

\section{Introduction}

Due to the world growing demand for electricity consumption, as well as environmental issues, researches and applications have been developed in relation to renewable energy sources use, such as hydropower, biomass, wind, sea and photovoltaic.

Taking into account this scenario, photovoltaic energy have been considered one of the most important available renewable energy sources, mainly because of the conversion of solar energy into electricity can be considered clean and does not degrades the environment. In addition, it has high reliability. Because of these aspects, many countries have used grid-connected PV systems for supplying of extra electrical energy [1]-[4]. On the other hand, PV arrangements suffer with their nonlinear voltage-current $(\mathrm{I} \times \mathrm{V})$ characteristic curves. Besides, they are strongly influenced by solar radiation and temperature conditions changes [5].
Another important aspect to be considered is related to the PV array efficiency, which usually is considered low, such as around $13 \%$ to $18 \%$. Thus, several techniques have been developed, in order to obtain the maximum power point tracking (MPPT) [6].

One of these MPPT techniques is known as Perturb and Observe $(\mathrm{P} \& \mathrm{O})$. This method, besides having a good power tracking, is also easy to be implemented. The main disadvantage of this method is the loss of energy caused by the oscillations around the point of maximum power. In situations where the PV arrangements are submitted to partial shading, this method does not ever converge to the maximum global power point [7].

Thereby, this work presents an alternative MPPT technique by using the Particle Swarm Optimization (PSO) method [8]. The proposed technique find the maximum global power point, when the PV arrangement is submitted, for example, to partial shading condition. Some MPPT PSO-based methods have been presented in the literature [9]-[12]. However, the methodology used in this present study covers different approach with regard to its form of implementation, as well as in the number of particles used to find the maximum global power point.

The sections presented in this work are described as follows: section 2 presents the mathematical model that describes the nonlinear behavior of the PV system, as well as its characteristic curves $(\mathrm{I} \times \mathrm{V})$ and $(\mathrm{P} \times \mathrm{V})$. The behavior of PV arrangements before and after partial shading condition, as well as the way for identifying the local and global maximum power points are presented in section 3. In section 4 is presented the control system adopted in this work, where the PV arrangement is connected to a dc-dc Boost converter. In section 5, P\&O and PSO-based MPPT methods are described, while in section 6, the PSO-based MPPT method is compared to the $\mathrm{P} \& \mathrm{O}$ method by means of numerical simulations. Finally, the conclusions are presented in section 7. 


\section{PV Cell Model}

The characteristics of PV cells can be represented by distinct electrical circuit models [13]-[14]. The simplest PV cell model can be represented by a current source placed with an anti-parallel diode. On the other hand, in most cases it is required the use of a model that describes the non-linear behavior of a PV cell. It is done by introducing both series and shunt resistances [5], as shown in Figure 1.

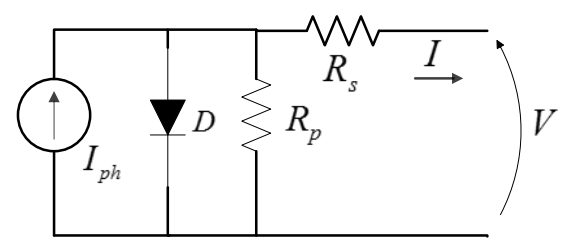

Fig. 1. Solar cell equivalent electrical circuit.

The output current of the PV cell is given by (1).

$$
I=I_{p h}-I_{r} *\left[e^{q *\left(\frac{V+I * R_{s}}{\eta * k * T}\right)-1}\right]-\frac{\left(V+I * R_{s}\right)}{R_{p}}
$$

Where:

$V, I$ - Output voltage and current of the PV cell;

$I_{p h}$ - Photocurrent;

$I_{r}$ - Reverse saturation current of the PV cell;

$R_{s}, R_{p}-$ Series and shunt resistances;

$q$ - Electron charge, $1.6 \times 10^{-19} \mathrm{C}$;

$\eta$ - Ideality factor of the $\mathrm{p}-\mathrm{n}$ junction;

$k$ - Boltzmann constant, $1.38 \times 10^{-23} \mathrm{~J} / \mathrm{K}$;

$T$ - Environment temperature, $\mathrm{K}$.

The current $I_{p h}$, represented by (2), is directly related with the solar radiation and temperature on the PV array surface. The reverse saturation current $\left(I_{r}\right)$ and reverse current $\left(I_{r r}\right)$ are described by (3) and (4), respectively.

$$
\begin{gathered}
I_{p h}=\left[I_{s c}+\alpha *\left(T-T_{r}\right)\right] * \frac{G_{s u n}}{1000} \\
I_{r}=I_{r r}\left(\frac{T}{T_{r}}\right)^{3} * e^{\left[\frac{q * E_{G}}{\eta * k} *\left(\frac{1}{T_{r}}-\frac{1}{T}\right)\right]} \\
I_{r r}=\frac{I_{s c}-\frac{V_{c a}}{R_{p}}}{e^{\frac{q * V_{o c}}{\eta * * * T_{r}}}}
\end{gathered}
$$

where $I_{s c}$ is the short circuit current at STC $\left(T_{r}=25{ }^{\circ} \mathrm{C}\right.$, and $\left.G_{\text {sun }}=1000 \mathrm{~W} / \mathrm{m}^{2}\right) ; V_{o c}$ is the open circuit voltage; $\alpha$ is the temperature coefficient; $T_{r}$ is the temperature reference, $298 \mathrm{~K} ; G_{\text {sun }}$ represents the power density of the solar radiation $(\mathrm{W} / \mathrm{m})^{2}$ and $E_{G}$ is the Band gap energy, 1.1 eV.

The solution of the equations that represents the mathematical PV model results in the non-linear characteristic curve $\mathrm{I} \times \mathrm{V}$ of the photovoltaic cell, as shown in Figure 2. The maximum power point $\left(P_{M P P}\right)$ represents the operation point in which the PV system operates at maximum power.

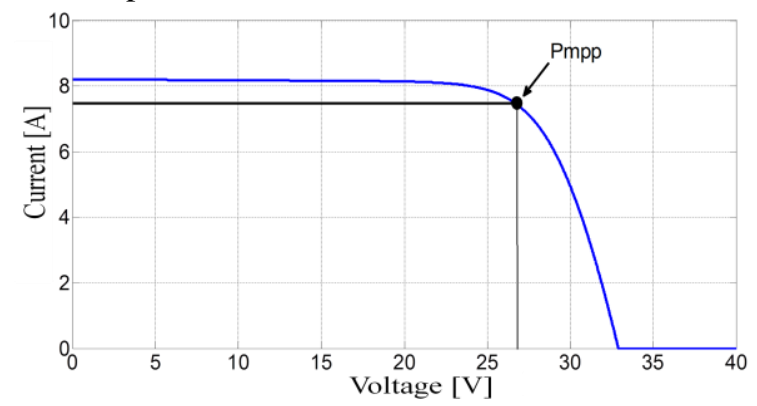

Fig. 2. Characteristic curve (IxV) of PV arrangement, without partial shading.

The parameters, such as solar radiation and temperature, presented in the mathematic model, are considered as inputs of the PV system, and are responsible for shaping the characteristic curve IxV [5]. Figure 3 shows the relationship between the PV voltage and current for different values of solar radiation. Figure 4 also shows the behavior of the characteristic curve $\mathrm{IxV}$ considering different values of temperature.

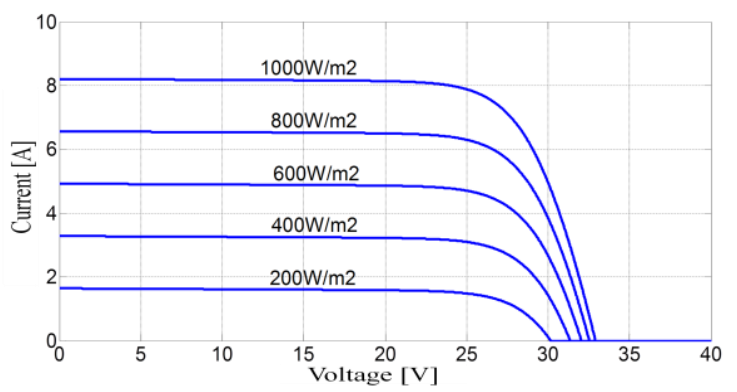

Fig. 3. Characteristic curve (IxV) of PV array for different values of solar radiation without partial shading.

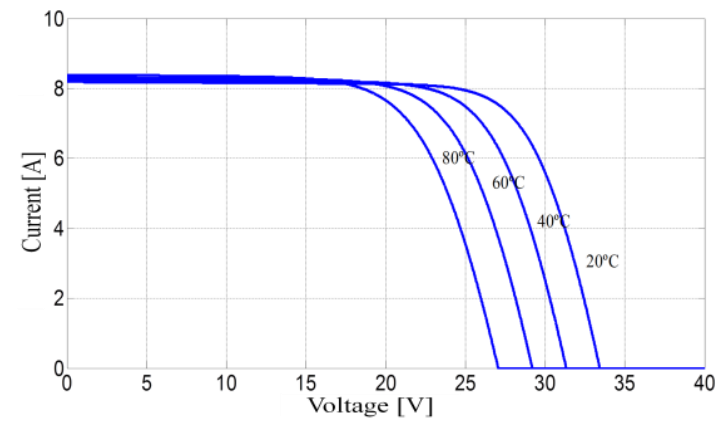

Fig. 4. Characteristic curve (IxV) of PV array for different values of temperature without partial shading.

As can clearly be observed in the Figure 3 the PV voltage at MPP is slightly modified for solar radiation changes, while the PV current varies significantly. On the other hand, from Figure 4, it can be noted that variations in the temperature affect the PV voltage at MPP significantly, while the PV current remains almost constant. Therefore, when these variations are uniform, the characteristic curve IxV will have only one point of maximum power, which can change according to both solar radiation and temperature conditions. Thus, it is necessary the use of specific techniques for tracking the PV array at maximum power point. However, when partial shading occurs, the energy available in the PV array is reduced. In addition, 
the characteristic curve IxV of the PV arrangement can also be changed, appearing global and local points of MPP. Hence, this condition can lead to improper operation of the algorithm used to track the MPP.

\section{Partial Shading of PV array}

In many applications, the PV array can be associated in series, in order to increase the output voltage of the system. Parallel combinations of PV panels are used to increase the output current of the system. Besides, the PV array can combine series and parallel connections to provide the desired voltage and current.. In this work it was adopted three PV panels connected in series submitted to partial shading. It was considered different levels of solar radiation for each PV panel, such as $1000 \mathrm{~W} / \mathrm{m}^{2}, 300$ $\mathrm{W} / \mathrm{m}^{2}$ and $700 \mathrm{~W} / \mathrm{m}^{2}$. Figure 5 shows the PV array considered in this work, and Table I summarizes its main parameters at standard test conditions (STC) .

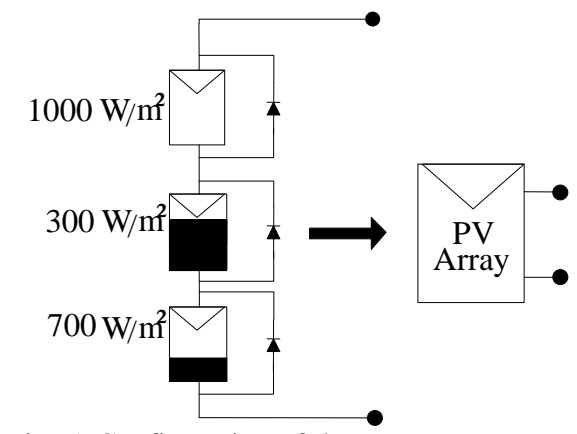

Fig. 5. Configuration of the $\mathrm{PV}$ arrangement.

Table I. - Standard test conditions (STC) of the SolarWorld Sunmodule Plus SW 245 PV module.

\begin{tabular}{|c|c|}
\hline Maximum PV power & $P_{\max }=245 \mathrm{~W}$ \\
\hline Maximum power point voltage & $V_{m p p}=30.8 \mathrm{~V}$ \\
\hline Maximum power point current & $I_{m p p}=7.96 \mathrm{~A}$ \\
\hline Open circuit voltage & $V_{o c}=37.5 \mathrm{~V}$ \\
\hline Short-circuit current & $I_{s c}=8.49 \mathrm{~A}$ \\
\hline
\end{tabular}

Figure 6 shows the $\mathrm{P} \times \mathrm{V}$ curve of the PV system considering the PV arrangement shown in Figure 5. As can be observed, due to the partial shading, the PxV curve presents multiple peaks of power, which are called as global and local maximum power points. Therefore, an efficient MPPT method must track the global maximum point instead tracking in any local maximum point.

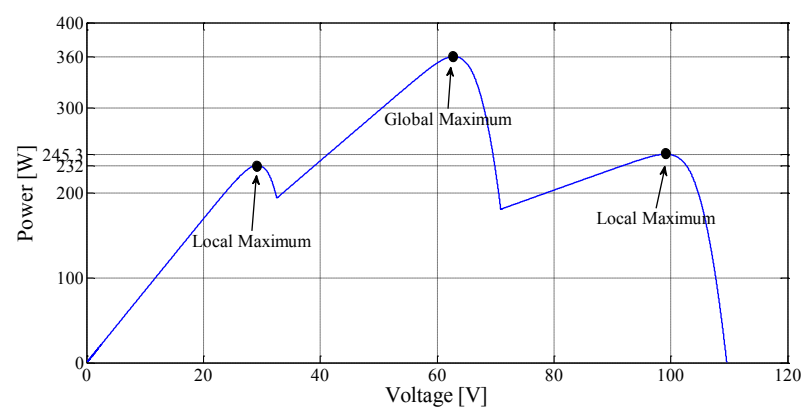

Fig. 6. Curve $\mathrm{P} x \mathrm{~V}$ of the $\mathrm{PV}$ array with partial shading.

The PV curve presented in Figure 6 shows three points of maximum power, such as the point of global maximum power $(360 \mathrm{~W})$, and other two points of local maximum power $(232 \mathrm{~W}$ and $245.3 \mathrm{~W})$. Thus, the main objective of this work is to find and to operate ever at the global maximum power point, in order to extract the overall available PV array energy.

\section{Control configuration of the PV grid- connected system}

The complete PV grid-connected system is shown in Figure 7. The PV array is composed of three series PV panels connected to the step-up dc-dc Boost converter, which is used to perform the MPPT. The electrical energy disposable at the output terminals of the PV array is injected into the grid as active energy. The PV system is grid-connected by means of a full-bridge inverter with L type filter.

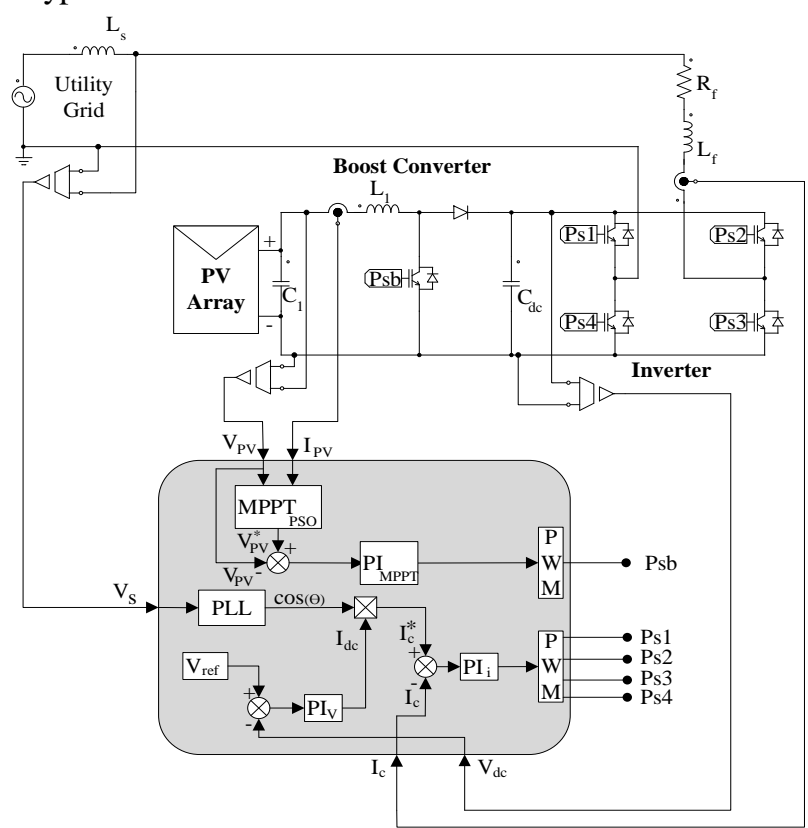

Fig. 7. PV grid-connected system.

The main goal of the Boost converter is to extract the maximum power from the PV array. Since the dc-bus voltage is not controlled by means of the dc-dc converter, its amplitude could change. Thereby, the full-bridge inverter by using the dc-bus loop control keeps the dcbus voltage at constant value. For this purpose the dc-bus control operates by increasing or decreasing the reference value of the current used to inject the active energy into the utility grid. Thus, in conjunction with Phase-Locked Loop (PLL) system the dc-bus loop control generates the current reference used in the inverter current control loop [15]. The PLL algorithm generates a sinusoidal reference, which is synchronized with the utility voltage. Both dcbus and current control loops use the ProportionalIntegral (PI) controllers in their structures. The PI controllers are designed by means of Bode diagram, where the crossover frequency and phase margin are used as design parameters to find the values of proportional and integral gains [16]. Table II summarizes the main PV grid-connected system parameters used in the simulation tests, including the Boost and inverter parameters, as well as the gains of the PI controllers used in both dc-bus and current control loops. 
Table II. - PV grid-connected system parameters.

\begin{tabular}{|c|c|}
\hline Nominal utility voltage (rms) & $V_{s}=127 \mathrm{~V}$ \\
\hline Nominal utility frequency & $f=60 \mathrm{~Hz}$ \\
\hline Grid inductance & $L s=10 \mu \mathrm{H}$ \\
\hline Inverter Inductive filter & $L_{f}=1.5 \mathrm{mH}$ \\
\hline Resistance of inductive filter & $R_{f}=0.22 \Omega$ \\
\hline MPP dc-bus voltage & $V_{d c}=230 \mathrm{~V}$ \\
\hline dc-bus capacitor & $C_{d c}=2300 \mu \mathrm{F}$ \\
\hline Inverter Switching frequency & $f_{s i}=20 \mathrm{kHz}$ \\
\hline $\begin{array}{c}\text { Desired crossover frequency } \\
\text { (Current PI controller) }\end{array}$ & $\omega_{c i}=7850 \mathrm{rad} / \mathrm{s}$ \\
\hline $\begin{array}{c}\text { Desired phase-margin } \\
\text { (Current PI controller) }\end{array}$ & $P M_{i}=67^{\circ}$ \\
\hline dc-bus PI controller gains & $k_{P v}=0.271 ; k_{I v}=1.42$ \\
\hline $\begin{array}{c}\text { Desired crossover frequency } \\
\text { (dc-bus controller) }\end{array}$ & $\omega_{c v}=150.79 \mathrm{rad} / \mathrm{s}$ \\
\hline $\begin{array}{c}\text { Desired phase-margin } \\
\text { (dc-bus controller) }\end{array}$ & $P M_{v}=88^{\circ}$ \\
\hline PV filter capacitor & $C_{l}=100 \mu \mathrm{F}$ \\
\hline Boost Inductance & $L_{l}=2.4 \mathrm{mH}$ \\
\hline Boost Switching frequency & $f_{s b}=30 \mathrm{kHz}$ \\
\hline
\end{tabular}

\section{MPPT Techniques - P\&O and PSO Methods}

In this section, the MPPT algorithms based on $\mathrm{P} \& \mathrm{O}$ technique and PSO method are discussed.

\section{A. MPPT-P\&O Technique}

$\mathrm{P} \& \mathrm{O}$ method is based on periodical increment or decrement of the output terminal voltage of the PV cell and comparing the power obtained in the present cycle with the power of the previous one. If the voltage varies and the power increases, the control system changes the operating point in that direction. Otherwise, it changes the operating point in the opposite direction. Since the direction of the voltage change is known, the voltage is varied at a constant rate. The constant rate parameter should be adjusted to ensure the balance between faster response and less fluctuation in steady state. A scheme of the MPPT-P\&O algorithm is shown in Figure 8. It can be observed that the changing of power and voltage varies the duty cycle $(D)$ of the Boost converter. The increment or decrement of $D$ should be adjusted to reduce the oscillations of the system and optimize the MPPT operation.

\section{B. PSO optimization method}

PSO is a population-based stochastic optimization algorithm for global optimization [8]. It is based on the behavior of social groups like fish schools or bird flocks. The fact which is recursively exploited is that an improved performance can be gained by interactions between individuals, or more specifically by imitation of successful individuals. The particles movement are based on (4) and (5) [8].

$$
\begin{gathered}
v_{i}^{k+1}=w \cdot v_{i}^{k}+\emptyset_{1} \cdot R_{1} \cdot \text { Pbest }_{i}+\emptyset_{2} \cdot R_{2} \cdot \text { Gbest }_{i} \\
x_{i}^{k+1}=x_{i}^{k}+v_{i}^{k+1}
\end{gathered}
$$

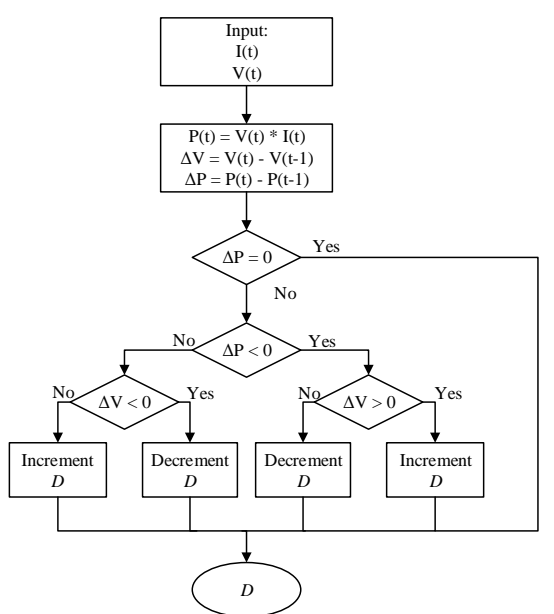

Fig. 8. Scheme of the MPPT-P\&O algorithm.

where: $v$ is the adjusted speed of the particle; $\emptyset_{1}$ and $\emptyset_{2}$ are the acceleration coefficients regarding the best particles and the best global positions influences in the velocity updating, respectively. $R_{1}$ and $R_{2}$ are random variables with uniform distribution; $R_{1}$ and $R_{2} \in[0,1]$; Pbest and Gbest are the best global position and the best local position found until the $i$ th iteration by fitness function, respectively; $w$ is the inertia weight of the previous velocity in the present speed calculation. In order to elaborate further about the inertia weight it can be noted that a relatively larger value of $w$ is helpful for global optimum, and lesser influenced by the best global and local positions, while a relatively smaller value for $w$ is helpful for convergence, i.e., smaller inertial weight encourages the local exploration as the particles are more attracted towards Pbest and Gbest. Hence, in order to achieve a balance between global and local search abilities, a linear inertia weight decreasing with the algorithm convergence evolving was adopted, which has demonstrated good global search capability at beginning and good local search capability latter iterations.

In the MPPT PSO-based the initial particles values of voltage magnitudes are obtained within the PV system range of operation. Besides, the outputs reference $\left(\mathrm{V}_{\text {ref }}\right)$, given by (6) are the voltages when occurs the convergence of the method.

$$
x^{k}=\left[\begin{array}{llll}
V_{\text {ref } 1}^{k} & V_{\text {ref } 2}^{k} & \cdots & V_{\text {refn } n}^{k}
\end{array}\right]
$$

where $n$ is the number of particles of the PSO method.

The PSO convergence is based on the objective function or fitness function. In this work the objective function compares the power delivered the PV system with the power delivered from the $\mathrm{PV}$ in previous iteration, as shown by (7)

$$
P_{p v}^{k}>P_{p v}^{k-1}
$$

Finally, the stopping criterion is defined in (8),

$$
\frac{P_{p v}{ }^{k-1}-P_{p v}^{k}}{P_{p v}^{k}}>\Delta P
$$


where $P_{p v}{ }^{k-1}$ is the power obtained in the previous iteration; $P_{p v}^{k}$ is the power obtained in the actual iteration and $\Delta P$ is a minimum error. It was considered $\Delta P=0.1$. The suitable values for the PSO input parameters, such as acceleration coefficients, $\emptyset_{1}$ and $\emptyset_{2}$, weight inertia, $w$, and population size, regarding to the MPPT optimization problem are illustrated in the Table III. These parameters are obtained in the literature [8].

Table III. - Parameters of the PSO Method

\begin{tabular}{|c|c|}
\hline Parameters & Value \\
\hline$\emptyset_{1}$ & 2 \\
\hline$\emptyset_{2}$ & 1.8 \\
\hline$w$ & 0.8 \\
\hline Number of particles & 3 \\
\hline
\end{tabular}

The algorithm of Figure 9 describes the functioning of MPPT-PSO technique applied in this work.

After the generation of the PV reference voltage $V_{\text {ref }}$, it is compared with the voltage of the actual PV system. A PI controller is used to minimize the error, by adjusting the output voltage of the Boost converter acting on the dutycycle.

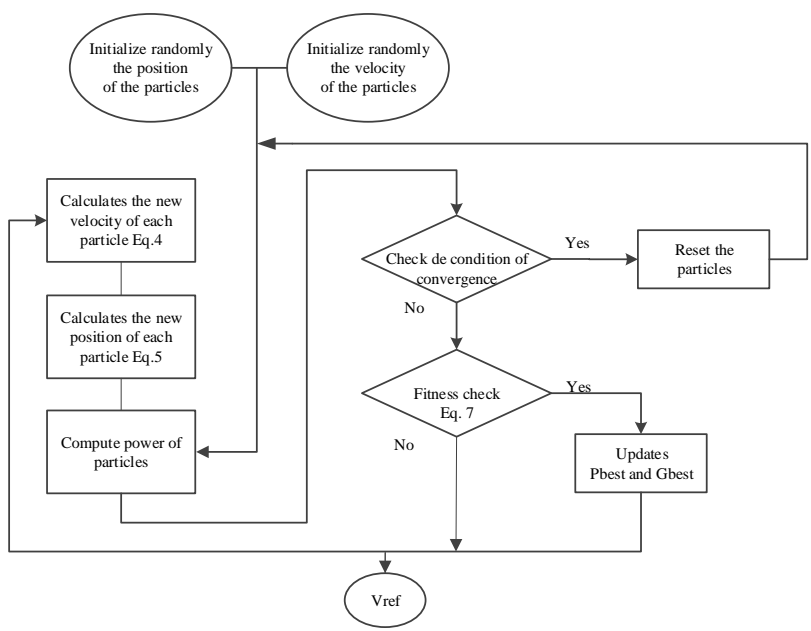

Fig. 9. Flowchart of the PSO method applied to the PV system.

\section{Simulation Results}

Considering the PV arrangement presented in Figure 5, three tests were carried out for different solar radiation conditions:

- Case 1: 3 panels with $1000 \mathrm{~W} / \mathrm{m}^{2}$;

- Case 2 : 1 Panel with $1000 \mathrm{~W} / \mathrm{m}^{2}, 1$ with 700 $\mathrm{W} / \mathrm{m}^{2}$ and 1 with $300 \mathrm{~W} / \mathrm{m}^{2}$;

- Case 3: 1 Panel with $1000 \mathrm{~W} / \mathrm{m}^{2}, 1$ with 500 $\mathrm{W} / \mathrm{m}^{2}$ and 1 with $750 \mathrm{~W} / \mathrm{m}^{2}$.

In Figure 10 are presented the PxV curves of the PV arrangement for the three conditions of solar radiations.

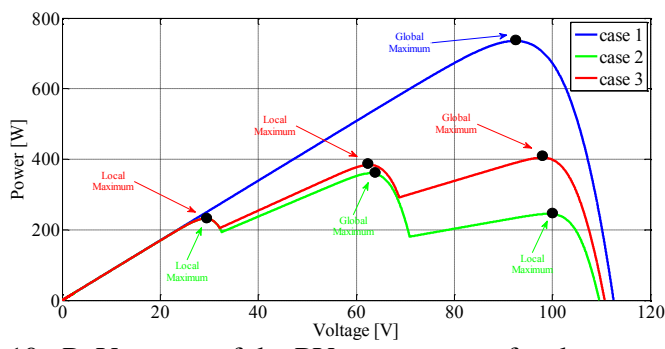

Fig. 10. PxV curves of the PV arrangement for the cases 1,2 and 3 .

Figure 11 shows the power extracted from the PV arrangement using the MPPT-P\&O technique, considering variations on solar radiation over the time in according with the three presented cases. It is noted that the MPPT-P\&O extracts the maximum power from PV array for the case $1(735 \mathrm{~W})$ and for the case $3(404 \mathrm{~W})$. This happens because the behavior of the PV arrangement during the initialization has only one point of maximum power (global). However, at the moment of transition from the case 1 to the case 2, there are other points of local maximums, and the MPPT-P\&O algorithm converges to the closest maximum power point, extracting a maximum power of $244 \mathrm{~W}$. During the transition from case 2 to case 3 , the operating point of the actual system converges to the global maximum power point of the case $3(404 \mathrm{~W})$, which at the moment is the closest point to convergence. Finally, in the transition from case 3 to case 1 the MPPT-P\&O technique converges to the global point of maximum $(735 \mathrm{~W})$, because there is no local maximum power point. During the simulation, it can be noticed that the MPPT-P\&O technique generates greater oscillation on the PV power when compared with the MPPT- PSO technique. The oscillations occur due to the increment and decrement of the duty cycle used to control the Boost converter. Figure 12 shows the PV operation points, in which the system converges after the transitions between the three presented cases considering partial shading conditions. Figure 13 shows the maximum power point tracking of PV considering the MPPT-PSO technique. As can be noted the method has converged to all maximum global points. Fig. 14 shows the convergence operation point, in which the PV system has converged after the transitions between the presented cases, considering partial shading conditions.

Figure 15 shows the injection of power into the grid obtained from the energy extracted the PV system by using the MPPT-PSO technique. As can be noted the injected current into the grid is in opposite phase to the utility voltage.

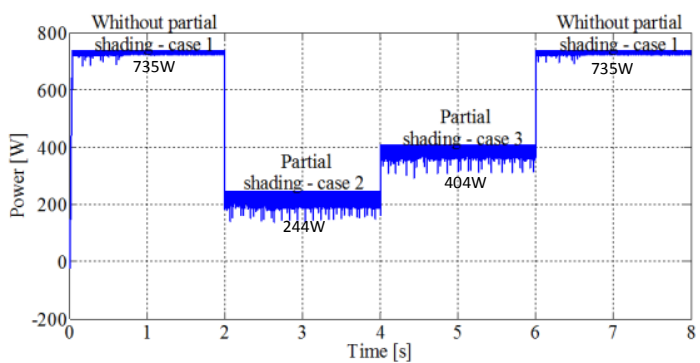

Fig. 11. PV power extraction using P\&O MPPT technique. 


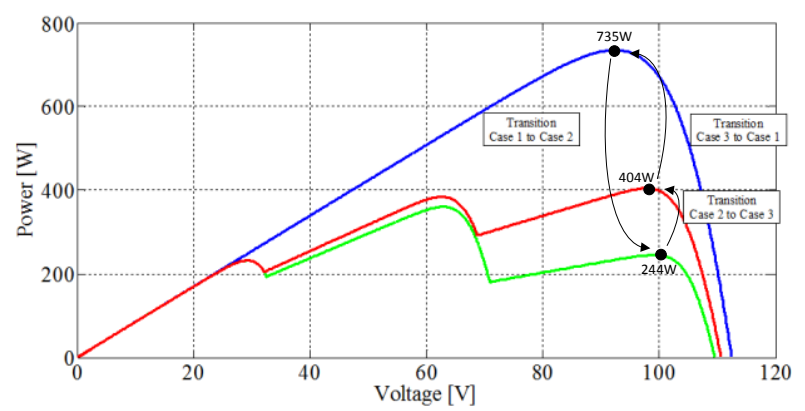

Fig. 12. Convergence operation points during the transitions between the three cases using the MPPT-P\&O method.

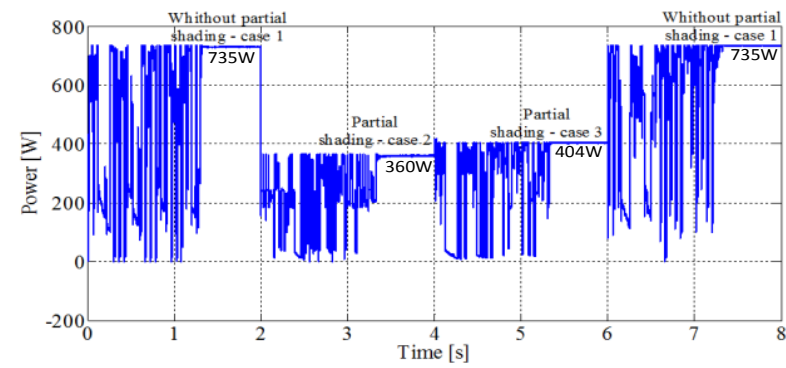

Fig. 13. PV power extraction using PSO MPPT technique.

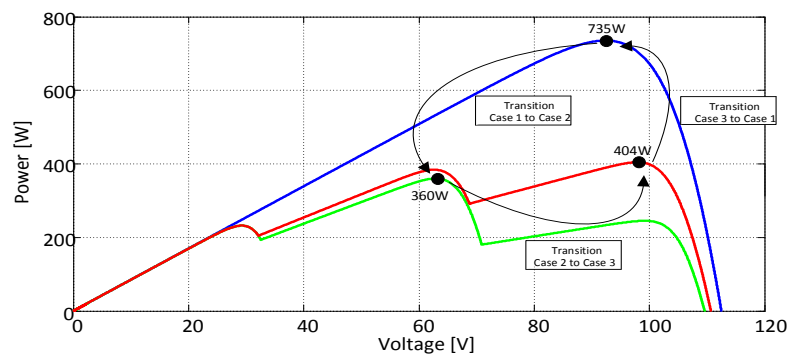

Fig. 14. Convergence operation points during the transitions between the three cases using the MPPT-PSO method.

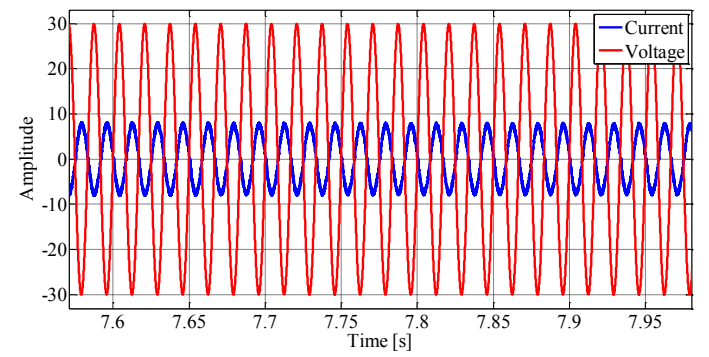

Fig. 15. Single-phase utility grid current (10 A/div) and voltage $(60 \mathrm{~V} / \mathrm{div})$.

\section{Conclusion}

The proposed MPPT-PSO technique achieved better use of the available energy provided by the presented PV system. It was possible the extracting of the global maximum power from the PV array considering partial shading conditions. In addition, it was observed a smaller power oscillation around the power drained from the PV array at the MPP in steady state. In real conditions, it is not feasible to disregard the effect of partial shading in PV arrangements, which can cause significant impacts on the PV array power extraction. Thus, the MPPT-PSO technique proposed in this work proved to be robust and efficient in relation to the extracting of the maximum power in PV arrays submitted to partial shading conditions.

\section{References}

[1] L. Bangyin, D. Shanxu, and C. Tao, "Photovoltaic DCbuilding-modulebased BIPV system-concept and design considerations," IEEE Trans. Power Electron., vol. 26, no. 5, pp. 1418-1429, May 2011.

[2] Z. Li, S. Kai, X. Yan, F. Lanlan, and G. Hongjuan, "A modular gridconnected photovoltaic generation system based on DC bus," IEEE Trans. Power Electron., vol. 26, no. 2, pp. 523-531, Feb. 2011.

[3] J. L. Agorreta, M. Borrega, J. López and and L. Marroyo, "Modeling and control of N-paralleled grid-connected inverters with LCL filter coupled due to grid impedance in PV plants," IEEE Trans. Power Electron., vol. 26, no. 3 , pp. 770-785, Mar. 2011.

[4] E. Serban and H. Serban, "A control strategy for a distributed power generationmicrogrid application with voltage- and current-controlled sourceconverter," IEEE Trans. Power Electron., vol. 25, no. 12, pp. 2981-2992, Dec. 2010.

[5] M. M. Casaro and D. C. Martins, "Modelo De Arranjo Fotovoltaico Destinado a Análises em Eletrônica de Potência via Simulação," Revista Eletrônica de Potência, vol. 13, no. 3, pp. 141-146, Aug. 2008 (in portuguese).

[6] M. A. G. Brito, L. Galotto Jr, L. P. Sampaio, G. A. Melo and C. A. Canesin, "Evaluation of the Main MPPT Techniques for Photovoltaic Applications," IEEE Trans. Ind. Electron., vol. 60, no. 3, pp. 1156-1167, March 2013.

[7] J. Young-Hyok, J. Doo-Yong, K. Jun-Gu, K. Jae-Hyung, L. Tae-Won, and W. Chung-Yuen, "A real maximum power point tracking method for mismatching compensation in PV array under partially shaded conditions," IEEE Trans. Power Electron., vol. 26, no. 4, pp. 1001-1009, Apr. 2011.

[8] J. Kenned and R. Eberhart, "Particle swarm optimization", in Proc. of IEEE International Conference on Neural Networks, vol. 4, 1995, pp. 1942-948.

[9] M. Miyatake, M. Veerachary, F. Toriumi, N. Fujii and H. Ko, "Maximum Power Point Tracking of Multiple Photovoltaic Arrays: A PSO Approach," IEEE Trans. Aerosp. Electron. Syst. Mag, vol. 47, no. 1, pp. 367-380, Jan. 2011.

[10] K. Ishaque, Z. Salam, M. Amjad and S. Mekhilef, "An Improved Particle Swarm Optimization (PSO)-Based $M P P T$ for PV With Reduced Steady-State Oscillation," IEEE Trans. Power Electron., vol. 27, no. 8, pp. 3627-3638, Aug. 2012.

[11] Yi-Hwa Liu, Shyh-Ching Huang, Jia-Wei Huang and Wen-Cheng Liang, "A Particle Swarm Optimization-Based Maximum Power Point Tracking Algorithm for PV Systems Operating Under Partially Shaded Conditions," IEEE Trans. Energy Convers., vol. 27, no. 4, pp. 1027 1035, Dec. 2012.

[12] K. L. Lian, J. H. Jhang and I. S. Tian, "A Maximum Power Point Tracking Method Based on Perturb-and-Observe Combined With Particle Swarm Optimization," IEEE J. Photovolt., vol. 4, no. 2, pp. 626-633, Mar. 2014.

[13] J. A. Gow and C. D. Manning, "Development of a Photovoltaic Array Model for Use in Power Electronics Simulation Studies," IEE Proc. on Electric Power Applications, vol. 146, no. 2, p. 193-200, Mar. 1999.

[14] G. J. Yu, Y. S. Jung, I. Choi and J. H. Song, "A Novel Two-Mode MPPT Control Algorithm based on Comparative Study of Existing Algorithms", In Proc. of PVSC 2002, vol. 29, 2002, pp. 1531-1534.

[15] V. D. Bacon, S. A. O. da Silva, L. B. G. Campanhol and B. A. Angélico, "Analysis and performance evaluation of a single-phase phase-locked loop algorithm using a nonautonomous adaptive filter," IET Trans. on Power Electronics, vol. 7, no. 8, pp. 2081-2092, Aug. 2014.

[16] B. A. Angélico; L. B. G. Campanhol and S. A. O. Silva, "PI/PID Tuning Procedure of a Single-Phase Shunt Active Power Filter Using Bode Diagram," IET Trans. on Power Electronics, vol. 7, no. 10, pp. 2647-2659, Oct. 2014. 